\title{
Why We Speak
}

\author{
Rohit Parikh \\ City University of New York \\ Brooklyn College and \\ CUNY Graduate Center \\ rparikh@gc.cuny.edu
}

\begin{abstract}
We explain the relevance of Nash, Hoare and others in explaining Gricean implicature and cheap talk. We also develop a general model to address cases where communication is not cooperative, i..e cases of deception as well as cases where there is common knowledge of different interests in speaker and hearer. Tow models, one qualitative and one quantitative are introduced.
\end{abstract}

\section{Introduction}

In his book Making the Social World, John Searle indicates that speech acts have two directions. There is the world to word direction, as in the statement "the cat is on the chair" which is true if the world is as the sentence says it is, i.e., the cat is indeed on the chair. There is also a word to world direction as in "Please shut the door" where the relevant proposition becomes true when the door is closed. The speech act seeks to change the world rather than represent it. However, an utterance even of "The cat is on the chair" can be seen as having a word to world direction in that it could be a way to prevent someone from sitting in the chair, and hence on the cat. An utterance is a social act and seeks to change the mental states of listeners and perhaps, eventually, change their actions. So it has the same word to world direction as a request or a command. This fact was noticed originally by Wittgenstein with his language games, but he characteristically refused to give a more formal account. But he was followed by Austin, by Searle himself and various game theorists like Crawford, Farrell and Sobel. Clearly if an utterance has a word to world direction, then it is a move in a game and can be of interest to game theorists. Thus, paradoxically, a sentence and an utterance are of opposite types in Searle's terminology

\section{A Taxonomy}

The simplest case is where an utterance merely seeks to inform someone of something. Suppose a sentence $\mathrm{A}$ is uttered, the listener already believes $\mathrm{T}$ and $\mathrm{A}$ is consistent with $\mathrm{T}$. Then the listener moves from $\mathrm{T}$ to $\mathrm{T}+\mathrm{A}$, the logical closure of $\mathrm{T}$ $\cup\{\mathrm{A}\}$. The listener has been informed of A. ${ }^{1}$

If $\mathrm{T}$ is not consistent with $\mathrm{A}$ then the listener may apply a revision operator a la AGM (Alchourron et al, 1985) and go from $\mathrm{T}$ to $\mathrm{T}-\mathrm{A}$ (which reduces $\mathrm{T}$ to a subtheory not containing $\neg \mathrm{A}$ and then adds $A$ to that subtheory) Note that in the second case, some formula B which was in $\mathrm{T}$ will no longer be in $\mathrm{T}-\mathrm{A}$ and it could have been the aim of the speaker to achieve the deletion of $\mathrm{B}$ more than the addition of $\mathrm{A}$ in the listener. To a man expecting his wife any moment, one could say "Her flight has been delayed by 3 hours," the intention being to remove from him the belief that he will see her at 4 PM.

As we see, even the base case has complexities which Frege did not anticipate. But there is more, namely the phenomenon of implicature noticed and investigated by Paul Grice. Since the utterance of $\mathrm{A}$ is a move, the listener not only knows that A has been said, but that it has been said under the particular circumstances of the conversation and can typically infer more than just $\mathrm{A}$ and it logical consequences. A motorist says to a pedestrian, "My car is out of gas" and the pedestrian responds, "There is a gas station around the corner."

\footnotetext{
${ }^{1} \mathrm{My}$ usage here is the reverse of Searle's own usage but will seem more natural to those used to functions. In the one case the world is operating on the word to give it a truth value and in the other case the word is operating on the world to make it as desired. Some of the material in this paper has been presented in various venues but is unpublished. Some other material, especially the model is new.
} 
Grice points out that the implicature is that the gas station is open as far as the pedestrian knows, for otherwise why say what she has said. An example from Pinker et al is where a representative of the mob comes around to a store owner and says, "Nice store you have here. It would be a pity if something were to happen to it." The store owner already knows that it would be a pity and does not need to be told. Here the message is in the fact that it is said at all and by whom. The implicature is likely to be something like "Give us $\$ 500$ every month and you will be fine."

Deborah Tannen in her You Just Don't Understand gives an example of a husband and wife travelling along a highway when they are nearing a restaurant. "Are you hungry?" says the wife. "No," says the husband and drives on. Later on he is puzzled why she is angry. Here it is clear that the signaling mechanism has not been sufficiently established between husband and wife. He should have said, "No, I am not hungry, but maybe you are?" Should we call this also an example of an implicature? If it is then it is one which did not succeed for Grice asks that implicatures should be calculable. Clearly the husband failed in his calculation, or else it was not a genuine implicature in Grice's sense.

A particularly interesting but also difficult case is where the utterance takes advantage of something like a Nash equilibrium of communication and understanding.

Prashant Parikh gives an example of a man saying, "I am going to the bank" where bank could mean a financial institution or a river bank.

There are four possible situations here. It is good if the speaker means financial institution and the listener understands financial institution. A bad one is where the speaker means financial institution and the listener understands river bank. There are two more cases, one good and one bad. It requires cooperation on the part of the speaker and listener to agree to a good interpretation and not a bad one. Perhaps common knowledge is involved, perhaps something else.

A final case is one discussed by both Austin and Searle. A minister says to a couple, "I now pronounce you man and wife." Here the minister is not reporting on the world, nor is he suggesting a future action. His statement is the action which changes the world in the required way.

Can there be a general theory which deals with all these cases? Perhaps there is no general theory, but we want to suggest that there might well be a general framework of which these are all special cases. The general framework is one where there is an existing social situation and the speaker is using the utterance as a way of altering the situation in some way. One way the utterance can be seen is as an operator applying to a situation $\mathrm{S}$ and creating a new situation S'.

However, the "bank" example and the Deborah Tannen example show that the situation contemplated by the speaker might not be the one which does arise. So then we should think of an utterance as non-deterministic operator which converts the existing situation $S$ into one of (a finite number of) situations $\left\{S_{1} ; S_{2} ; \ldots S_{n}\right\}$. Perhaps the speaker intends $S_{1}$ and what comes about is $S_{2}$. The speaker might then have to repair the damage, or it may happen that the damage is not easy to repair.

In the movie When Harry Met Sally, Harry tells his friend Sally that she is a very attractive person. "You are coming on to me!" says Sally. And when Harry offers to take it back she says,"You can't take it back; it is already out there now!" Harry does manage a repair but it takes him the rest of the movie.

The notion of situation needed here would necessarily be rich to handle all these cases. Something which would work in most cases would be a contemplated game (or action) with a state of knowledge (belief?) for the various actors, their preferences (which might remain constant) and a set of permitted sequences of action. What a particular actor would do (after an utterance) then would depend on his perception of the (new) situation. As Parikh and Tasdemir point out, the action of an agent can be manipulated by changing her state of information, a point made also by Shakespeare in his Much Ado about Nothing, where the actions of Benedick and Beatrice are changed by changing their beliefs.

\section{Information versus Action}

In this paper, we shall consider the cases where the first speaker $\mathbf{A}$ has some goal in mind which is common knowledge, and the second speaker $\mathbf{B}$ makes a statement which is relevant to this goal. In that case the (common) knowledge of the goal is part of the context and is typically used to calculate the implicature.

Prashant Parikh and Benz and van Rooij do 
point out that some implicatures might help someone to make a decision even though other implicatures might just be informational.

It will turn out that some contributions made by the computer scientist Tony Hoare and by the economist John Nash will be relevant. The connection of implicatures with these two eminent scholars seems to have been overlooked thus far in the literature.

\subsection{Hoare Semantics}

Here is how Hoare semantics enters. A Hoare assertion takes the form

$$
\{X\} \alpha\{G\}
$$

where $X, G$ are propositions, $X$ is the precondition, $G$ is the goal and $\alpha$ is a contemplated action (actions are programs for Hoare).

Formally, $S$ is a state space, $X, G$ are subsets of $S$, and $\alpha$ becomes a relation $R_{\alpha}$ on $S$.

Then the Hoare condition is

$(\forall s)(\forall t)\left(s \in X \&(s, t) \in R_{\alpha} \rightarrow t \in G\right)$

If $X$ holds when the program starts, then $G$ will hold when it finishes.

Now $\mathbf{A}$ wants to reach $G$ using $\alpha$. We will assume that $G$ is common knowledge between $\mathbf{A}$ and $\mathbf{B}$, and $\mathbf{B}$ has some information which would affect the possibility of reaching $G$.

This could happen in four ways.

1. $\mathbf{B}$ has part of the information which implies a suitable $X$. Thus $\mathbf{B}$ is supporting both the goal and the action.

2. B has information which would cause $\mathbf{A}$ to modify $\alpha$ in some way (e.g. to replace it by a more specific action, or, technically, a subaction.)

3. B has information which suggests a particular action $\alpha$ to $\mathbf{A}$.

4. B has information which would cause $\mathbf{A}$ to abandon the method $\alpha$. (Which may mean abandoning the goal altogether or using some completely unrelated method.)

B volunteers information which indicates whether 1) or 2) or 3) or 4) is the case and leaves A to

1. Either supply some other information which will complete the process of deducing $X$ or
2. modify $\alpha$ in some way, or

3. Conclude that $\neg\{X\} \alpha\{G\}$.

This other information or the modification, or $\neg\{X\} \alpha\{G\}$ is the implicature.

And note that the modification is not in itself a proposition, it may be an imperative. Thus part of our thesis is that while an implicature may be a proposition, it might well be something else which affects $\mathbf{A}$ in some way.

\section{The Cooperative Case}

Here we assume, as Grice does, that the utilities of $\mathbf{A}$ and $\mathbf{B}$ are in accord. We do not assume that they are the same since what $\mathbf{A}$ gains from receiving the information is likely to be much more than the pleasure that $\mathbf{B}$ gets from helping out.

Consider the case of the motorist. The goal of the motorist ${ }^{2}$ is clear. She wants to fill her tank with gas. The statement which $\mathbf{B}$ makes points to an algorithm, go around the corner and get gas there. Here it is unclear whether A should walk there carrying a gas can, or has at least enough gas to drive around the corner. But in either case, going around the corner is indicated (by $\mathbf{B}$ ) as the $\alpha$.

Our Hoare assertion is

$$
\left\{X_{1} \& X_{2} \& X_{3}\right\} \alpha\{G\}
$$

Where $X_{1}$ is that there is a gas station around the corner, $X_{2}$ is that the gas station is open and $X_{3}$ is that $\mathbf{A}$ has enough money to pay for the gas.

Only $\mathbf{A}$ knows whether $X_{3}$ is true and this is not B's business. B has volunteered $X_{1}$. It is obvious that $\alpha$ is useless unless $X_{2}$ is true. Since $\mathbf{B}$ has indicated that he supports the action $\alpha$ it follows that $X_{2}$ is true as far as $\mathbf{B}$ knows. If he is not supporting the action then he should not have said $X_{1}$. So in this case $X_{2}$ is the implicature.

\subsection{The Hiring Problem}

In this example $\mathbf{A}$ is the chair of the hiring committee for some college, $\mathbf{B}$ is a professor and $\mathbf{C}$ is the professor's student who is an applicant for a position at A's college. $\mathbf{B}$ writes about $\mathbf{C}$

He has excellent handwriting and he always came to class on time.

\footnotetext{
${ }^{2}$ In Grice's original version
} 
Here A's goal $\mathbf{G}$ is to have a colleague who will be a good teacher and researcher, $\alpha$ is the action of hiring $\mathbf{C}$, and the precondition is that $\mathbf{C}$ is a good philosopher.

B's statement does not give A the information which A needs, or even supports it in some relevant way, and the implicature is that the precondition is false. A should abandon $\alpha$. The implicature is $\neg\{X\} \alpha\{G\}$ where $X$ is any true condition.

But why doesn't $\mathbf{B}$ simply say, "He is not a good philosopher"? Clearly because B is C's teacher and professional ethics preclude him from saying something negative about $\mathbf{C}$. What he does instead is to say something positive which is not good enough.

Here is a joke which makes a similar point.

A tired and depressed looking man walks into a restaurant and sits down. A waiter comes over and asks what the man wants.

"Two scrambled eggs with rye toast, and a kind word," says the man.

After a while the waiter comes back and puts an order of eggs and rye toast before the man.

As the waiter is walking away, the man says, "What about the kind word?"

"Don't eat them eggs," says the waiter.

Just like the professor, the waiter is forbidden to say something negative about the restaurant. but his "don't eat them eggs" carries the implicature that the eggs are not good, may even cause illness. And that indeed is a kind word.

\subsection{Modifying $\alpha$}

We note that in many cases actions are not disjoint from each other. If we think of a (nondeterministic) action as a binary relation on the state space, then two actions may be disjoint, may overlap, or one may be included in the other.

One Hoare-like rule is

$$
\{X\} \alpha\{G\}, \beta \subseteq \alpha
$$

$$
\{X\} \beta\{G\}
$$

If a correctness condition is satisfied by $\alpha$ then it is also satisfied by a subaction $\beta$ but not necessarily vice versa.

Here is an example.
A to $\mathbf{B}$, "I am thinking of going to Times square by public transport."

B, "Buses will be very slow during the rush hour."

A likely implicature is "Take the subway."

Here action $\alpha$ is the action of taking some public transport, $\beta$ is the action of taking the subway and $\gamma$ is the action of taking a bus. ${ }^{3} \alpha$ is the union of $\beta$ and $\gamma$.

Let $X$ be the current situation, and $G$ be the goal of getting to Times square on time. Then $\{X\} \beta\{G\}$ is true, but $\{X\} \alpha\{G\}$ is not ${ }^{4}$. B is suggesting that the action be changed from $\alpha$ to $\beta$ by eliminating $\gamma$.

When an action satisfies a Hoare condition then so does a sub-action. But this is not the case if we are trying to maximize expected utility. It is quite possible that the expected utility of $\alpha$ is higher than that of $\beta$ even though $\beta \subseteq \alpha$.

For example, if I am betting on a horse, then it is better to choose a horse at random than to choose a specific horse which is well known to be a nag.

However, if satisficing is our desired condition then subactions would be at least as good as an action. If all outcomes of $\alpha$ are satisfactory, and $\beta$ is a subaction of $\alpha$ then all outcomes of $\beta$ are also going to be satisfactory.

\section{Nash Bargaining}

In Grice's treatment of implicature, he assumes a principle of cooperation. Thus for one of his first examples, when a motorist says, "My car is out of gas" and the pedestrian replies "There is a gas station around the corner," there is an implicature that the station is open. And this follows from the presumption that the pedestrian's desires are the same as those of the motorist, although perhaps less intense and so the pedestrian wants the motorist to get gas for his car. This tradition has been followed in much of the subsequent literature.

However, there are exceptions. The economics literature on cheap talk no longer assumes that the utilities are aligned. What the speaker wants and what the listener wants need no longer be fully aligned, although some overlap is necessary for communication to take place at all. Stalnaker in

\footnotetext{
${ }^{3} \mathrm{We}$ assume it to be common knowledge that a taxicab is out of the question given the traffic.

${ }^{4}$ This is a consequence of the nondeterminism of the two actions. $\beta$ is guaranteed to achieve the goal whereas $\alpha$ might but is not guaranteed to do so.
} 
his paper Cheap talk and credibility, follows this tradition as well.

Yet as we noted, some degree of cooperation is requisite, for otherwise why communicate at all?

We would like to suggest a slight generalization of the Grice principle which looks like it might bridge the gap between cooperation and strategizing. This principle was originally formulated by John Nash in his paper "The Bargaining problem."

In Nash's framework two players $\mathbf{A}$ and $\mathbf{B}$ are trying to decide on a point in two space. There is a convex set $\mathrm{S}$ of possible solutions and each point $\mathrm{p}$ in $\mathrm{S}$ yields utilities $\mathrm{u}(\mathrm{p}), \mathrm{v}(\mathrm{p})$ to $\mathbf{A}$ and $\mathbf{B}$ respectively. Nash presumes that the actual bargain, i.e. the point $p$ which is finally chosen will be Pareto optimal. That is to say, Nash assumes that there is no $\mathrm{q}$ in $\mathrm{S}$ such that $u(q) \geq u(p)$ and $v(q)>v(p)$ or that $u(q)>u(p)$ and $v(q) \geq v(p)$. There is no way to make one person better off without making the other person worse off.

Nash assumes moreover that the space $\mathrm{S}$ is convex. $^{5}$

Using very natural axioms on the solution concept Nash proves that the final bargain will be the unique point $p$ such that $u(p) \times v(p)$ is maximum.

It is obvious that assuming that the players are choosing a Pareto optimal point, and there are at least two such, then there is a conflict. Neither can gain without the other losing.

The element of cooperation enters through Nash's notion of a fallback point. The fallback point $\mathrm{F}$ is the point to which they "fall back" in case they cannot arrive at a bargain, and this point is worse (for both) than any other point in S.

Thus cooperation arises through the fact that both players want to avoid the fallback point and each needs the help of the other to achieve this.

Grice's cooperative principle is a special case of Nash's. For suppose the utilities are aligned. I.e., if for any two points $\mathrm{p}$ and $\mathrm{q}$ we have $u(q)>u(p)$ iff $v(q)>v(p)$, then the Nash bargaining point which maximizes the product $u(p) \times v(p)$ is also

\footnotetext{
${ }^{5}$ To take an example rather like that of Nash's original example. Suppose that the two are restricted to a point in the set $\{(x, y) \mid 2 x+y \leq 3\}$. The utilities are $x$ for $\mathbf{A}$ and $y$ for $\mathbf{B}$. The fallback point is $(0,0)$. Then the Pareto optimal points will be all the points on the line $2 x+y=3$. But which particular point should be chosen? The product of the utilities is maximized at the point $(.75,1.5)$.

But Nash does not speak about communication and there is no guarantee even that a Pareto optimal point will be reached, let alone Nash's "ideal" point. To take a real life example, it seems highly unlikely that a Pareto optimal point will be reached in Ukraine.
}

the point which maximizes $u(p)$. B gains by helping $\mathbf{A}$ to gain. The pedestrian helps the motorist to get gas for the sake of the small pleasure of helping another ${ }^{6}$.

But as we noted this is not the only case. The mere fact that the players both want to avoid $\mathrm{X}$ does not imply that their utilities are fully aligned.

We now offer an example of how the Nash principle works.

Suppose that an American tourist is in India and wants to buy a carved wooden elephant. He has already seen such an elephant in a store for Rs. 500 but sees a hawker selling the identical elephant for Rs. 400.

It is customary to bargain with hawkers but what should the tourist offer? ${ }^{7}$

In this situation, the fallback situation is that the tourist abandons the hawker and buys his elephant in the store. But the hawker himself has bought the elephant for Rs. 40 and so any price paid from 41 rupees to 499 rupees would be better for both than the fallback situation, which is no sale for the hawker and a cost of Rs. 500 for the tourist.

The element of cooperation arises because both parties want to avoid the fallback situation, but given this fact there is an element of conflict in that the hawker wants to charge more and the tourist wants to pay less.

Here we assume that the utilities of $\mathbf{A}$ and $\mathbf{B}$ are not aligned although there must be some concord for communication to take place at all. ${ }^{8}$

\section{A Model}

In the following I am going to make two assumptions and offer a caveat.

1. Each party in a two way conversation expects to benefit from the conversation.

2. This expectation is common knowledge.

3. But the benefit might not be common knowledge and might not even be true.

Thus suppose Ann says something, A, to Bob in response to a query. Then Bob believes that he has benefited by hearing $\mathrm{A}$ (which, in normal cases

\footnotetext{
${ }^{6}$ See for instance Tomasello, (2009)

${ }^{7}$ In a similar situation, Aumann offered 200, the offer was accepted and Aumann bought the elephant, only to find that the proper price would have been Rs. 50 .

${ }^{8}$ We do not consider the important and interesting case where $\mathbf{A}$ thinks they are aligned but they are not.
} 
would also mean that Bob believes he benefits by believing A).

And Ann, even if she does not benefit as much expects to suffer no loss.

Thus suppose that the two of them were in states $(\mathrm{S}, \mathrm{T})$ before A was said, and are now in states ( $\mathrm{S}^{\prime}, \mathrm{T}^{\prime}$ ), then Bob believes that $\mathrm{T}$ ' is better for him than $\mathrm{T}$ and this is common knowledge. And Ann believes that $S^{\prime}$ is not worse for her than $S$, and this too is common knowledge.

In a cooperative dialogue, and if Ann is well informed, then both these beliefs will be true. They could be false if Ann was mistaken about A, and Bob believed her, or if Ann was trying to mislead Bob by saying $A$ and he was not aware that she was doing so.

In order to define notions of better and worse we need a notion of pragmatic belief.

A pragmatic belief for Bob is a formula of the form $X(a)=u$ which means that performing action a will yield utility $\mathrm{u}$ to Bob. If Bob has $\mathrm{n}$ actions $\left(a_{1}, a_{2}, a_{n}\right)$ available then a pragmatic state of belief is a map $X$ from $\left\{a_{1}, \ldots, a_{n}\right\}$ into the real numbers.

A statement A made by Ann will cause a change from one state $S$ of pragmatic belief to another state $S^{\prime}$.

"But doesn't the statement A cause a change in Bob's beliefs about the world?" To be sure it does. But it might not mean the addition of A to Bob's beliefs if Bob does not believe Ann. Or it might mean the addition of more than $\mathrm{A}, \mathrm{A}+\mathrm{A}^{\prime}$ where $\mathrm{A}^{\prime}$ is the implicature. And finally, the change in Bob's state of beliefs will eventuate in a change in what he would do and why.

If Ann tells Bob that the bridge is closed, he does normally come to believe that the bridge is closed and hence not plan to take the bridge to the other side. But it is his plan not to take the bridge which will be our central concern. If Bob had had no intention of going to the other side, he would wonder why Ann had said that the bridge was closed.

So facts result in actions, and it is actions that will be our main concern.

So let us suppose that Bob's initial pragmatic state of beliefs was S, Ann's saying A changes it to $S$ ' and the true state is $S$ ". So let

$S=\left\{\left(a_{1}, u_{1}\right),,\left(a_{n}, u_{n}\right)\right\}$

$S^{\prime}=\left\{\left(a_{1}, u_{1}^{\prime}\right),,\left(a_{n}, u_{n}^{\prime}\right)\right\}$
$S "=\left\{\left(a_{1}, u{ }_{1}\right),,\left(a_{n}, u{ }_{n}\right)\right\}$

Let $\mathrm{m}$ be Bob's best action according to $\mathrm{S}, \mathrm{m}$ ' be the best action according to $S$ '.

Thus suppose that $u_{3}$ is the largest of $u_{1}, . ., u_{n}$, and $u_{5}^{\prime}$ is the largest of $u_{1}^{\prime},, u_{n}^{\prime}$ then $\mathrm{m}$ is $a_{3}$ and $\mathrm{m}$ ' is $a_{5}$.

Then Bob's gain in utility is

$S "(m ')-S "(m)$.

Bob was thinking according to $\mathrm{S}$ and would have done $\mathrm{m}$. After hearing A he will now do $\mathrm{m}$. But his real utilities should be evaluated according to $S "$.

\section{Applications of the Model}

Consider the case of the motorist and the pedestrian. Initially the motorist had two options. To keep driving hoping to come to a gas station and go around the corner. Let these actions be a and b. Then a has the higher utility for him since he has no reason to think that $b$ would do him any good. After hearing Ann say, "There is a gas station around the corner," presumably his new best action would be b. If it would still be a then why should Ann bother to speak? Ergo b has a higher utility. But, that is so only if the gas station is open.

Consider the case of the person who wants to go to Times Square. She has two options. To take the subway and take the bus. Perhaps they are equally viable or at least both have a high enough utility. But now consider the remark "buses will be slow during the rush hour." That lowers the utility of the bus and makes the subway the decisive choice.

This model does not yet accommodate cases like that of the tourist in India since bargaining goes beyond mere converation. But we hope to deal with it in the next version of the paper.

The other cases are similar and can be dealt with by looking at utilities and actions.

\section{A Comparison}

We have offered two models to understand the phenomena of implicature and cheap talk. The first model was based on Hoare and was qualitative. We do not need to assign numbers to the value of getting faster to Times Square. The second model makes shameless use of numerical utilities. Of course the first model is more general and would apply also to situations where we have no idea of utilities or probabilities. But the second model has the potential for clean mathematical results. 
Acknowledgements We thank Nicholas Allott, Anton Benz, Luciana Belotti, Michael Devitt, Stephen Neale, Prashant Parikh, Steven Pinker, Adriana Renero, Robert Stainton and Cagil Tasdemir for comments.

\section{References}

Nicholas Allott. 2006. Game theory and communication. In Benz, Jäger, and van Rooij, editors, Game Theory and Pragmatics, pages 123-152. Palgrave Macmillan, London.

Carlos E. Alchourrn, Peter Grdenfors, and David Makinson. 1985. On the logic of theory change: Partial meet contraction and revision functions. Journal of Symbolic Logic 50(2): 510-530.

Anton Benz and Robert van Rooij. 2007. Optimal assertions and what they implicate. Topoi 26(1), 63-78.

Joseph Farrell and Matthew Rabin, 1996, Cheap talk, Journal of Economic Perspectives 10(3), 103-118.

Paul Grice,1989, Studies in the Way of Words, Harvard U. Press, Cambridge, Mass

C. A. R. Hoare, An axiomatic basis for computer programming,1969, Communications of the Association for Computing Machinery, 12(10), 576-580.

John Nash,1950, The bargaining problem, Econometrica, 18(2), 155-162.

Rohit Parikh, Cagil Tademir, and Andreas Witzel, 2013, The power of knowledge in games, 2013, International Game Theory Review 15(4), 1-28.

Steven Pinker, MA Nowak and JJ Lee, 2008 The logic of indirect speech, Proceedings of the $\mathrm{Na}$ tional Academy of Sciences, 105(3), 833-838.

Prashant Parikh,2001 The Use of Language, CSLI, Stanford.

John Searle, 2010, Making the social world: The structure of human civilization, Oxford University Press, Oxford

Robert Stalnaker, 2006, Saying and meaning, cheap talk and credibility, In Benz, Jäger and van Rooij, editors, Game Theory and Pragmatics, pages 83-100, Palgrave Macmillan, London

Micchal Tomasello, 2009, Why we cooperate. MIT press, Cambridge, MA 